\title{
Encapsulation of volatile fission products in a two-dimensional dicalcium nitride electride
}

\author{
Navaratnarajah Kuganathan ${ }^{1,2 *}$, Alexander Chroneos $^{1,2}$ and Robin W. Grimes ${ }^{1}$ \\ ${ }^{1}$ Department of Materials, Imperial College London, London, SW7 2AZ, United Kingdom \\ ${ }^{2}$ Faculty of Engineering, Environment and Computing, Coventry University, Priory Street, Coventry \\ CV15FB, United Kingdom
}

\begin{abstract}
The efficient capture of volatile fission products released during spent fuel reprocessing is a crucial concern for the nuclear community. Here we apply density functional theory to examine the efficacy of a two-dimensional dicalcium nitride electride $\left(\mathrm{Ca}_{2} \mathrm{~N}: \mathrm{e}^{-}\right)$to encapsulate volatile fission products. Encapsulation is endoergic for $\mathrm{Kr}, \mathrm{Xe}, \mathrm{Rb}$ and $\mathrm{Cs}$ meaning that they are not encapsulated. Conversely, strong encapsulation is exhibited for $\mathrm{Br}$, I and Te with respect to their atoms and dimers as reference states. The preference for $\mathrm{Br}$, I and $\mathrm{Te}$ encapsulation is a consequence of charge transfer from $\mathrm{Ca}_{2} \mathrm{~N}: \mathrm{e}^{-}$to form encapsulated anions. This makes the electride a promising material for the selective trapping of volatile $\mathrm{Br}$, I and Te.
\end{abstract}

Keywords: Fission products; electride; $\mathrm{Ca}_{2} \mathrm{~N}: \mathrm{e}^{-}$; DFT; encapsulation energy;

*Corresponding author, e-mail: n.kuganathan@imperial.ac.uk 


\section{Introduction}

Spent nuclear fuel is reprocessed in order to extract the unused uranium and minimise the volume of radioactive waste. This process generates a substantial volume of fission product contaminants distributed in reactants, solvents and products [1-4]. Also, radiotoxic volatile fission products ( $\mathrm{Xe}, \mathrm{Kr}, \mathrm{Br}, \mathrm{I}, \mathrm{Rb}, \mathrm{Cs}$ and $\mathrm{Te}$ ) can escape from the fuel under a variety of circumstances, impacting on the environment as they disperse (as atoms, molecules or entrained in aerosol particles). Radioactive iodine is of particular concern as much is produced, it is highly active, highly mobile and concentrates in the human thyroid gland, thereby imparting significant local dose [2,5]. Caesium is also a fission product of concern as it too is highly active and its high chemical reactivity means it will remain bound near to surfaces $[6,7]$. It is therefore important to capture and dispose of radioactive volatile fission products, particularly iodine and caesium, effectively and safely.

Filters impregnated with charcoal are widely used to trap iodine in nuclear power plants owing to their low production cost and high surface area [8]. In order to improve the efficacy of filters for the capture of radioactive iodine, different filter materials such as zeolites, silica, alumina, metal organic frameworks and porous organic polymers have also been examined. [8, 9-11]. The efficiency of filters is dependent upon properties of the filter material with a desire for high thermal stability and robust mechanical properties, high capacity but also effective chemical retention. The search for new low cost filter materials is a central theme in reducing the potential impact of radioactive species.

Electrides are ionic crystals in which electrons serve as anions [12]. Based on the localization of electrons in the lattice, they are classified as: zero-dimensional (electrons residing in cavities)[13,14], one-dimensional (electrons occupying in a channel)[15,16] and twodimensional (electrons localising in a layer) $[\mathbf{1 7 , 1 8}]$. A wide range of applications including catalyst supports, electron emitters and super conductors have been reported for a zero dimensional "mayenite" type electride $\left[\mathrm{Ca}_{24} \mathrm{Al}_{28} \mathrm{O}_{64}\right]^{4+} \bullet\left(\mathrm{e}^{-}\right)_{4}[\mathbf{1 9 - 2 3}]$. In previous studies, we have used this electride to examine the effectiveness of encapsulation of volatile fission products [24,25], heavy metals [26], technetium [27] and lithium [28]. The first onedimensional electride $\left[\mathrm{La}_{8} \mathrm{Sr}_{2}\left(\mathrm{SiO}_{4}\right)_{6}\right]^{4+\bullet}\left(\mathrm{e}^{-}\right)_{4}$ was reported by Yaoqing et al. [16] though its practical utility was not fully studied.

A new class of two-dimensional dicalcium nitride electride $\left[\left(\mathrm{Ca}_{2} \mathrm{~N}\right)^{+} \cdot \mathrm{e}^{-}\right]$in which electrons delocalize between cationic framework layers was first reported by Lee et al. [29]. Owing to its promising characteristics such as stability at room temperature, low work function $(2.6$ $\mathrm{eV}$ ), open layer structure and high electron concentration, this electride has been used in 
promising applications such as chemical reduction reactions [30], sodium ion batteries [31] and solid lubricants [32].

In the present study, atomic scale modelling, based on a density functional theory (DFT) approach, is used to provide insights into the thermodynamical stability, charge transfer and electronic structures of volatile fission products encapsulated between layers in the $\mathrm{Ca}_{2} \mathrm{~N}: \mathrm{e}^{-}$ electride.

\section{Computational Methods}

DFT calculations were performed to find the energy minimised and electronic structures of $\mathrm{Ca}_{2} \mathrm{~N}: \mathrm{e}^{-}$with and without encapsulated species. The plane wave DFT code VASP (Vienna Ab initio Simulation Program) was used [33]. This solves the Kohn-Sham (KS) equations within the DFT framework and uses projected augmented wave (PAW) potentials [34] and plane wave basis sets (cut-off of $500 \mathrm{eV}$ ). A $8 \times 8 \times 4$ Monkhorst-Pack [35] $k$-point mesh which yielded 35 irreducible $k$ points was used. Further increase in the basis set cut-off and $k$-points resulted a total energy different of $0.9 \mathrm{meV}$ per atom. The exchange-correlation term was included in the form of generalized gradient approximation (GGA) as described by Perdew, Burke, and Ernzerhof (PBE)[36]. The conjugate gradient algorithm [37] was used to relax atomic positions and cell parameters with the aid of Hellman-Feynman theorem including Pulay corrections to obtain forces on the atoms. Forces on the atoms were smaller than 0.001 $\mathrm{eV} / \AA$ in all configurations. The stress tensor was less than $0.002 \mathrm{GPa}$ in all optimised structures. Short-range interactions were modelled using a semi empirical dispersion term as described by Grimme et al.[38]. All encapsulated structures were modelled using a $4 \times 4 \times 1$ supercell consisting of $96 \mathrm{Ca}$ and $48 \mathrm{~N}$ atoms. One of the limitations in this method is the supercell size. Accurate encapsulation energy is dependent on the supercell size. Current study considered a reasonable size of the supercell and the relative trend in the encapsulation energy will be consistent.

Encapsulation energies were calculated for single atoms encapsulated within $\mathrm{Ca}_{2} \mathrm{~N}: \mathrm{e}^{-}$through the following equation:

$E_{E n c}=E_{\left(X @ C a_{2} N: e^{-}\right)}-E_{\left(C a_{2} N: e^{-}\right)}-E_{(X)}$,

where $E_{\left(X @ C a_{2} N: e^{-}\right)}$is the total energy of a single fission atom encapsulated in a $4 \times 4 \times 1$ supercell of $\mathrm{Ca}_{2} \mathrm{~N}: \mathrm{e}^{-}, E_{\left(\mathrm{Ca}_{2} \mathrm{~N}: e^{-}\right)}$is the total energy of a $4 \times 4 \times 1$ supercell of $\mathrm{Ca}_{2} \mathrm{~N}: \mathrm{e}^{-}$and $E_{(X)}$ is the energy of an isolated gas phase fission atom.

\section{Results and discussion}

\subsection{Crystal structre of $\mathrm{Ca}_{2} \mathrm{~N}: \mathrm{e}^{-}$}


Dicalcium nitride exhibits a hexagonal layered crystal structure with the space group $R \overline{3} m$, as shown in Figure 1a. The experimentally reported lattice parameters are $a=b=3.6048 \AA$, $\mathrm{c}=19.2031 \AA, \alpha=\beta=90^{\circ}$ and $\gamma=120^{\circ}$ [29]. The layers in the crystal structure consist of $\mathrm{NCa}_{6}$ octahedra in the $a b$ plane, with a separation of $3.86 \AA$. In order to test the validity of the pseudopotentials and basis sets used in this study, the experimental crystal structure was energy minimised: calculated structural parameters are in excellent agreement with corresponding experimental values [29] as reported in Table 1. Two-dimensional electron layers and total DOS plot are shown in Figure $1 \mathrm{~b}$ and $1 \mathrm{c}$ respectively. $\mathrm{Ca}_{2} \mathrm{~N}: \mathrm{e}^{-}$exhibits metallic behaviour in agreement with a DFT study performed by Lee et al.[29]

\subsection{Encapsulation of single noble gas atoms ( $\mathrm{Kr}$ and $\mathrm{Xe})$}

Relaxed structures of $\mathrm{Ca}_{2} \mathrm{~N}: \mathrm{e}^{-}$encapsulated with $\mathrm{Kr}$ and $\mathrm{Xe}$ are shown in Figure 2. Both species exhibit positive encapsulation energies and are therefore unstable within the layers (see Table 2). The encapsulation energy is less unfavourable for $\mathrm{Kr}$ than Xe due to the smaller atomic radius of $\mathrm{Kr}$ than that of $\mathrm{Xe}[\mathbf{3 9}]$. This is further confirmed by the shorter Ca-Kr bond lengths and smaller volume change predicted for Kr. The small negative Bader charge [40] is indicative of the polarisation that these noble gas atoms are subject to between the layers. The smaller value for $\mathrm{Kr}$ reflects the smaller polarizability of $\mathrm{Kr}$.

Total DOS plots calculated for structures with Xe and Kr are almost identical to the DOS plot of encapsulant free $\mathrm{Ca}_{2} \mathrm{~N}: \mathrm{e}^{-}$. Atomic DOS plots show that $p$ - states belong to the $\mathrm{Kr}$ and Xe appear deep $(\sim-6 \mathrm{eV})$ in the valence band. Charge density plots show that encapsulation resulted in no significant change in the electron distribution between the layers.

\subsection{Encapsulation of halogen atoms (Br and I)}

Negative (favourable) encapsulation energies are calculated for $\mathrm{Br}$ and I, from their isolated atom reference states. This is a consequence of their strong electron affinities (see Table 3), reflected in the negative Bader charges. Both $\mathrm{Br}$ and I gain essentially one electron. This is because both $\mathrm{Br}$ and I can accept one electron to complete their stable $s^{2} p^{6}$ outer electronic configurations. The encapsulation energy calculated for $\mathrm{Br}$ is more favourable than that calculated for I due to its smaller atomic radius[39]. This is consistent with the shorter bond length of $\mathrm{Ca}-\mathrm{Br}$ than that calculated for $\mathrm{Ca}-\mathrm{I}$.

The encapsulation energy calculated using the dimer as the reference still indicates that both $\mathrm{Br}$ and $\mathrm{I}$ will occupy as $\mathrm{Br}^{-}$and $\mathrm{I}^{-}$ions despite the penalty to dissociate their diatomic molecules. The calculated dissociation energies (per atom) for $\mathrm{Br}_{2}$ and $\mathrm{I}_{2}$ are $1.26 \mathrm{eV}$ and 1.12 $\mathrm{eV}$ respectively. Br continues to exhibit a more preferable energy than I despite its higher dimer dissociation energy. 
Total DOS plots calculated for $\mathrm{Br}$ and I encapsulated configurations show that there is a reduction in the states associated with free electrons at the Fermi level, but these materials retain their metallic character (see Figure 3). This is further confirmed by the reduction of charge densities around the encapsulated atoms in the middle layer. There is a slight increase in overall volume upon encapsulation. The larger increase calculated for I is a consequence of its larger atomic radius.

\subsection{Encapsulation of Te atom}

Te exhibits a strongly favourable encapsulation energy (see Table 4). This is due to its high electron affinity and strong interaction with the lattice leading to a large Bader charge of -1.72. This means that it is tending to a stable $\mathrm{Te}^{2^{-}}$electronic configuration. The encapsulation energy calculated with respect to the dimer is still highly exothermic, despite the strong $\mathrm{Te}_{2}$ dissociation energy of $1.76 \mathrm{eV}$ per atom.

The total DOS plot (Figure 4) shows that the encapsulated configuration is still metallic as there are electrons left between layers. A single Te atom can gain only part of the interlayer electron density. Interestingly the volume increase for Te is larger than for I, reflecting the larger size of $\mathrm{Te}^{2-}$ than $\mathrm{I}^{-}$.

\subsection{Encapsulation of $\mathrm{Rb}$ and $\mathrm{Cs}$ atoms}

Finally, we considered encapsulation of $\mathrm{Rb}$ and $\mathrm{Cs}$. The relaxed structures are shown in Figure 5 and the encapsulation energies and the Bader charges are reported in Table 5 . Both $\mathrm{Rb}$ and Cs exhibit unfavourable encapsulation energies (2.09 $\mathrm{eV}$ and $2.18 \mathrm{eV}$ respectively). This is because of their low electron affinities and large size. In general, $\mathrm{Rb}$ ad $\mathrm{Cs}$ donate their outmost $s^{1}$ electrons to form stable noble gas electronic configurations. The interlayer space already has additional electrons so that rather than donate electrons both $\mathrm{Rb}$ and $\mathrm{Cs}$ end up with additional charges of -0.29 and -0.90 electrons respectively. Both $\mathrm{Rb}$ and $\mathrm{Cs}$ atoms are thus topologically frustrated in a sandwich formed by the $\mathrm{Ca}_{2} \mathrm{~N}$ layers. Consequently, the encapsulation becomes endoergic.

There is a perturbation in the total DOS and electron distribution noted for $\mathrm{Rb}$ (see figure 5). However, the resultant configuration is still metallic. In the case of Cs, both total DOS and charge distribution are not significantly changed.

\subsection{Encapsulation of dimers $\left(\mathrm{Br}_{2}, \mathrm{I}_{2}\right.$ and $\left.\mathrm{Te}_{2}\right)$}

We considered the encapsulation of $\mathrm{Br}$, I and $\mathrm{Te}$ in the form of dimers. The relaxed structures of dimers occupying the layer are shown in Figure 6. The encapsulation energies reported in Table 6 (calculated using the molecular reference state but normalised per atom) predict this 
mode of encapsulation is favourable and only slightly less favourable than when these anions are encapsulated as separated species (compare with energies in Tables 3 and 4). However, when encapsulated as an adjacent pair, the distance between the anions is significantly longer than the molecular dimer. Furthermore, the respective Bader charges (see Table 6) indicate that both anions in the pair assume negative charge - thus they are not molecules but pairs of adjacent anions. This suggests that the electride may be capable of accommodating high concentrations of these anions.

\section{Conclusion}

The efficacy of $\mathrm{Ca}_{2} \mathrm{~N}: \mathrm{e}^{-}$as a filter material to encapsulate volatile fission products was predicted using atomic scale simulation based on density functional theory with dispersion correction. While $\mathrm{Kr}, \mathrm{Xe}, \mathrm{Rb}$ and $\mathrm{Cs}$ are not favourably encapsulated, $\mathrm{Br}$, I and Te exhibit a strong affinity for encapsulation. Such strong encapsulation is evidenced by the significant charge transfer to the encapsulated atoms from the confined electrons between the layers, leading to the formation of stable $\mathrm{Br}^{-}, \mathrm{I}^{-}$and $\mathrm{Te}^{2-}$ ions. Exoergic encapsulation of dimers considered for $\mathrm{Br}$, I and Te led the formation of anion pairs rather than molecular species. In summary, $\mathrm{Ca}_{2} \mathrm{~N}: \mathrm{e}^{-}$electride encapsulates $\mathrm{Br}, \mathrm{I}$ and $\mathrm{Te}$ in the form of isolated gaseous atoms to form their stable negative ions. Other fission products ( $\mathrm{Kr}, \mathrm{Xe}, \mathrm{Rb}$ and $\mathrm{Cs}$ ) are not encapsulated. It is therefore $\mathrm{Ca}_{2} \mathrm{~N}: \mathrm{e}^{-}$electride can be of a candidate material to filter $\mathrm{Br}$, I and Te from effluent gases generated during spent nuclear fuel processing. This makes the electride a promising material for the selective trapping of volatile $\mathrm{Br}$, I and Te.

\section{Conflicts of interest}

The authors declare that there is no competing financial interest.

\section{Acknowledgements}

Computational facilities and support were provided by High Performance Computing Centre at Imperial College London.

\section{Data Availability Statement}

The data that support the findings of this study are available from the corresponding author upon reasonable request.

\section{References}

$1 \quad$ V.M. Erfrmenkov, IAEA Bull, 437 (1989).

2 M.I. Ojovan, W.E. Lee, An Introduction to Nuclear Waste Immobilisation, second ed., Elsevier, Oxford, U.K, 2014.

3 E. D. Collins, G. D. Del Cul, and B. A. Moyer, in Advanced Separation Techniques for Nuclear Fuel Reprocessing and Radioactive Waste Treatment, edited by K. L. Nash and G. J. Lumetta (Woodhead Publishing, 2011), p. 201.

$4 \quad$ C. Corkhill and N. Hyatt, in Nuclear Waste Management (IOP Publishing, 2018), p. 1.

5 B. H. Hamling and G. F. Jenkins, Journal of the Air Pollution Control Association 7, 256 (1958). 
C. D. Whitney and S. Landsberger, Journal of Radioanalytical and Nuclear Chemistry 280, 281 (2009).

K. Knebel, J. Jokiniemi, and P. D. Bottomley, Journal of Nuclear Science and Technology 56, 772 (2019).

A. Karhu, (NKSe13) Denmark, 1999.

J. Huve, A. Ryzhikov, H. Nouali, V. Lalia, G. Augé, and T. J. Daou, RSC Advances 8, 29248 (2018).

D. F. Sava, M. A. Rodriguez, K. W. Chapman, P. J. Chupas, J. A. Greathouse, P. S. Crozier, and T. M. Nenoff, Journal of the American Chemical Society 133, 12398 (2011).

B. H. M. Billinge, J. B. Docherty, and M. J. Bevan, Carbon 22, 83 (1984).

J. L. Dye, Science 247, 663 (1990).

A. Ellaboudy, J. L. Dye, and P. B. Smith, Journal of the American Chemical Society 105, 6490 (1983).

S. Matsuishi, Y. Toda, M. Miyakawa, K. Hayashi, T. Kamiya, M. Hirano, I. Tanaka, and H. Hosono, Science 301, 626 (2003).

J. Wang, K. Hanzawa, H. Hiramatsu, J. Kim, N. Umezawa, K. Iwanaka, T. Tada, and H. Hosono, Journal of the American Chemical Society 139, 15668 (2017).

Y. Zhang, Z. Xiao, T. Kamiya, and H. Hosono, The Journal of Physical Chemistry Letters 6, 4966 (2015).

T. Tada, S. Takemoto, S. Matsuishi, and H. Hosono, Inorganic Chemistry 53, 10347 (2014).

W. Ming, M. Yoon, M.-H. Du, K. Lee, and S. W. Kim, Journal of the American Chemical Society 138, 15336 (2016).

Y. Toda, H. Hirayama, N. Kuganathan, A. Torrisi, P. V. Sushko, and H. Hosono, Nature Communications 4, 2378 (2013).

M. Kitano, S. Kanbara, Y. Inoue, N. Kuganathan, P. V. Sushko, T. Yokoyama, M. Hara, and H. Hosono, Nature Communications 6, 6731 (2015).

N. Kuganathan, H. Hosono, A. L. Shluger, and P. V. Sushko, Journal of the American Chemical Society 136, 2216 (2014).

E. Feizi and A. K. Ray, Journal of Display Technology 12, 451 (2016).

M. Hara, M. Kitano, and H. Hosono, ACS Catalysis 7, 2313 (2017).

N. Kuganathan, A. K. Arya, M. J. D. Rushton, and R. W. Grimes, Carbon 132, 477 (2018).

N. Kuganathan, A. Chroneos, and R. W. Grimes, Scientific Reports 9, 13612 (2019).

N. Kuganathan, R. W. Grimes, and A. Chroneos, Journal of Applied Physics 125, 165103 (2019).

N. Kuganathan and A. Chroneos, Nanomaterials 9, 816 (2019).

N. Kuganathan and A. Chroneos, Energies 13, 1547 (2020).

K. Lee, S. W. Kim, Y. Toda, S. Matsuishi, and H. Hosono, Nature 494, 336 (2013).

Y. J. Kim, S. M. Kim, E. J. Cho, H. Hosono, J. W. Yang, and S. W. Kim, Chemical Science 6, 3577 (2015).

G. Chen, et al., ACS Applied Materials \& Interfaces 9, 6666 (2017).

J. Wang, L. Li, Z. Shen, P. Guo, M. Li, B. Zhao, L. Fang, and L. Yang, Materials 11, 2462 (2018).

G. Kresse and J. Furthmüller, Physical Review B 54, 11169 (1996).

P. E. Blöchl, Physical Review B 50, 17953 (1994).

H. J. Monkhorst and J. D. Pack, Physical Review B 13, 5188 (1976).

J. P. Perdew, International Journal of Quantum Chemistry 28, 497 (1985).

W. H. Press, S. A. Teukolsky, W. T. Vetterling, and B. P. Flannery, Numerical recipes in C (2nd ed.): the art of scientific computing (Cambridge University Press, 1992).

S. Grimme, J. Antony, S. Ehrlich, and H. Krieg, The Journal of Chemical Physics 132, 154104 (2010).

M. Mantina, A. C. Chamberlin, R. Valero, C. J. Cramer, and D. G. Truhlar, The Journal of Physical Chemistry A 113, 5806 (2009).

R. F. W. Bader, Theoretical Chemistry Accounts 105, 276 (2001). 
Table 1. Calculated lattice parameters and unit-cell volume of the hexagonal layered crystal structure (space group $R \overline{3} m$ ) of $\mathrm{Ca}_{2} \mathrm{~N}: \mathrm{e}^{-}$together with corresponding experimental values.

\begin{tabular}{|c|c|c|c|}
\hline Parameter & Calc & Expt [29] & $|\Delta|(\%)$ \\
\hline $\mathrm{a}=\mathrm{b}(\AA)$ & 3.6094 & 3.6048 & 0.13 \\
\hline $\mathrm{c}(\AA)$ & 19.2007 & 19.2031 & 0.01 \\
\hline$\alpha=\beta\left(^{\circ}\right)$ & 90.0 & 90.0 & 0.00 \\
\hline$\gamma\left({ }^{\circ}\right)$ & 120.0 & 120.0 & 0.00 \\
\hline $\mathrm{V}\left(\AA^{3}\right)$ & 216.62 & 216.11 & 0.24 \\
\hline
\end{tabular}


Table 2. Calculated electron affinities of $\mathrm{Kr}$ and Xe, encapsulation energies (calculated using the isolated gas phase atom as the reference), Bader charges on the encapsulated atoms, the shortest $\mathrm{Ca}-$ $\mathrm{X}$ bond distances $(\mathrm{X}=\mathrm{Kr}$ and $\mathrm{Xe})$ and relative volume changes upon encapsulation.

\begin{tabular}{|c|c|c|c|c|c|c|}
\hline $\begin{array}{c}\text { Fission } \\
\text { product }\end{array}$ & $\begin{array}{c}\text { Atomic } \\
\text { radius } \\
(\AA)[\mathbf{3 9}]\end{array}$ & $\begin{array}{c}\text { Electron } \\
\text { affinity } \\
(\mathrm{eV})\end{array}$ & $\begin{array}{c}\text { Encapsulation } \\
\text { energy }(\mathrm{eV})\end{array}$ & $\begin{array}{c}\text { Bader } \\
\text { charge } \\
(|\mathrm{e}|)\end{array}$ & $\begin{array}{c}\mathrm{Ca}-\mathrm{X} \\
(\AA)[\mathrm{X}=\mathrm{Kr} \\
\text { and Xe}]\end{array}$ & $\begin{array}{c}\text { Relative } \\
\text { volume } \\
\text { change } \\
(\Delta \%)\end{array}$ \\
\hline $\mathrm{Kr}$ & 2.02 & 1.08 & 1.86 & -0.32 & $3.00-3.07$ & 0.97 \\
\hline $\mathrm{Xe}$ & 2.16 & 1.24 & 2.48 & -0.44 & $3.06-3.11$ & 1.36 \\
\hline
\end{tabular}


Table 3. Calculated electron affinities of $\mathrm{Br}$ and I, encapsulation energies (calculated using the isolated gas phase atoms and dimers as reference states), Bader charges on the encapsulated atoms, the shortest $\mathrm{Ca}-\mathrm{X}$ bond distances $(\mathrm{X}=\mathrm{Br}$ and $\mathrm{I})$ and relative volume changes upon encapsulation.

\begin{tabular}{|c|c|c|c|c|c|c|c|}
\hline \multirow{2}{*}{$\begin{array}{c}\text { Fission } \\
\text { product }\end{array}$} & $\begin{array}{c}\text { Atomic } \\
\text { radius } \\
(\AA)[\mathbf{3 9}]\end{array}$ & \multirow{2}{*}{$\begin{array}{c}\text { Electron } \\
\text { affinity } \\
(\mathrm{eV})\end{array}$} & \multicolumn{2}{|c|}{$\begin{array}{c}\text { Encapsulation energy } \\
(\mathrm{eV} / \text { atom })\end{array}$} & \multirow{2}{*}{$\begin{array}{c}\text { Bader } \\
\text { charge } \\
(|\mathrm{e}|)\end{array}$} & $\begin{array}{c}\text { Ca-X } \\
(\AA)[\mathrm{X}=\mathrm{Br} \\
\text { and }]\end{array}$ & $\begin{array}{c}\text { Relative } \\
\text { volume } \\
\text { change }(\%)\end{array}$ \\
\hline $\mathrm{Br}$ & 1.83 & 4.97 & -4.67 & -3.41 & -1.09 & $2.92-2.99$ & 0.96 \\
\hline $\mathrm{I}$ & 1.98 & 4.65 & -3.34 & -2.22 & -1.12 & $3.00-3.05$ & 1.35 \\
\hline
\end{tabular}


Table 4. Calculated electron affinity of Te, encapsulation energy (calculated using the isolated gas phase atom and dimer as reference states), Bader charges on the Te atom, the shortest $\mathrm{Ca}-\mathrm{Te}$ bond distances and relative volume changes upon encapsulation.

\begin{tabular}{|c|c|c|c|c|c|c|c|}
\hline \multirow{2}{*}{$\begin{array}{l}\text { Fission } \\
\text { product }\end{array}$} & \multirow{2}{*}{$\begin{array}{l}\text { Atomic } \\
\text { radius } \\
(\AA)[39]\end{array}$} & \multirow{2}{*}{$\begin{array}{c}\text { Electron } \\
\text { affinity } \\
(\mathrm{eV})\end{array}$} & \multicolumn{2}{|c|}{$\begin{array}{c}\text { Encapsulation energy } \\
(\mathrm{eV} / \text { atom })\end{array}$} & \multirow{2}{*}{$\begin{array}{c}\text { Bader } \\
\text { charge } \\
(|\mathrm{e}|)\end{array}$} & \multirow{2}{*}{ Ca-Te $(\AA)$} & \multirow{2}{*}{$\begin{array}{c}\text { Relative } \\
\text { volume } \\
\text { change (\%) }\end{array}$} \\
\hline & & & atom & $\operatorname{dimer}\left(\frac{1}{2} \mathrm{Te}_{2}\right)$ & & & \\
\hline $\mathrm{Te}$ & 2.06 & 3.49 & -5.23 & -3.47 & -1.72 & $2.99-3.03$ & 1.47 \\
\hline
\end{tabular}


Table 5. Calculated electron affinities of $\mathrm{Rb}$ and $\mathrm{Cs}$, encapsulation energies (calculated using the isolated gas phase atoms), Bader charges on the encapsulated atoms, the shortest $\mathrm{Ca}-\mathrm{X}$ bond distances $(\mathrm{X}=\mathrm{Rb}$ and $\mathrm{Cs})$ and relative volume changes upon encapsulation.

\begin{tabular}{|c|c|c|c|c|c|c|}
\hline $\begin{array}{c}\text { Fission } \\
\text { product }\end{array}$ & $\begin{array}{c}\text { Atomic } \\
\text { radius } \\
(\AA)[\mathbf{3 9}]\end{array}$ & $\begin{array}{c}\text { Electron } \\
\text { affinity }(\mathrm{eV})\end{array}$ & $\begin{array}{c}\text { Encapsulation } \\
\text { energy }(\mathrm{eV})\end{array}$ & $\begin{array}{c}\text { Bader } \\
\text { charge }(|\mathrm{e}|)\end{array}$ & $\begin{array}{c}\text { Ca-X } \\
(\AA)[\mathrm{X}=\mathrm{Rb} \text { and } \\
\mathrm{Cs}]\end{array}$ & $\begin{array}{c}\text { Relative } \\
\text { volume } \\
\text { change }(\%)\end{array}$ \\
\hline $\mathrm{Rb}$ & 3.03 & 2.57 & 2.09 & -0.29 & $3.07-3.13$ & 1.09 \\
\hline $\mathrm{Cs}$ & 3.43 & 2.22 & 2.18 & -0.90 & $3.08-3.15$ & 1.15 \\
\hline
\end{tabular}


Table 6. Encapsulation energies and Bader charges calculated for dimers encapsulated in $\mathrm{Ca}_{2} \mathrm{~N}: \mathrm{e}^{-}$ layer.

\begin{tabular}{|c|c|c|}
\hline \multirow[b]{2}{*}{ Reaction } & \multirow{2}{*}{$\begin{array}{c}\text { Encapsulation energy } \\
\text { (eV/atom) with respect to } \\
\text { dimer }\end{array}$} & Bader charges $|\mathrm{e}|$ \\
\hline & & On both Br or I or Te atoms \\
\hline $\mathrm{Br}_{2}+\mathrm{Ca}_{2} \mathrm{~N}: \mathrm{e}^{-} \rightarrow \mathrm{Br}_{2} \cdot \mathrm{Ca}_{2} \mathrm{~N}: \mathrm{e}^{-}$ & -3.35 & $-1.00,-1.00$ \\
\hline $\mathrm{I}_{2}+\mathrm{Ca}_{2} \mathrm{~N}: \mathrm{e}^{-} \rightarrow \mathrm{I}_{2} \cdot \mathrm{Ca}_{2} \mathrm{~N}: \mathrm{e}^{-}$ & -2.18 & $-1.04,-1.04$ \\
\hline $\mathrm{Te}_{2}+\mathrm{Ca}_{2} \mathrm{~N}: \mathrm{e}^{-} \rightarrow \mathrm{Te}_{2} \cdot \mathrm{Ca}_{2} \mathrm{~N}: \mathrm{e}^{-}$ & -3.01 & $-1.60,-1.60$ \\
\hline
\end{tabular}



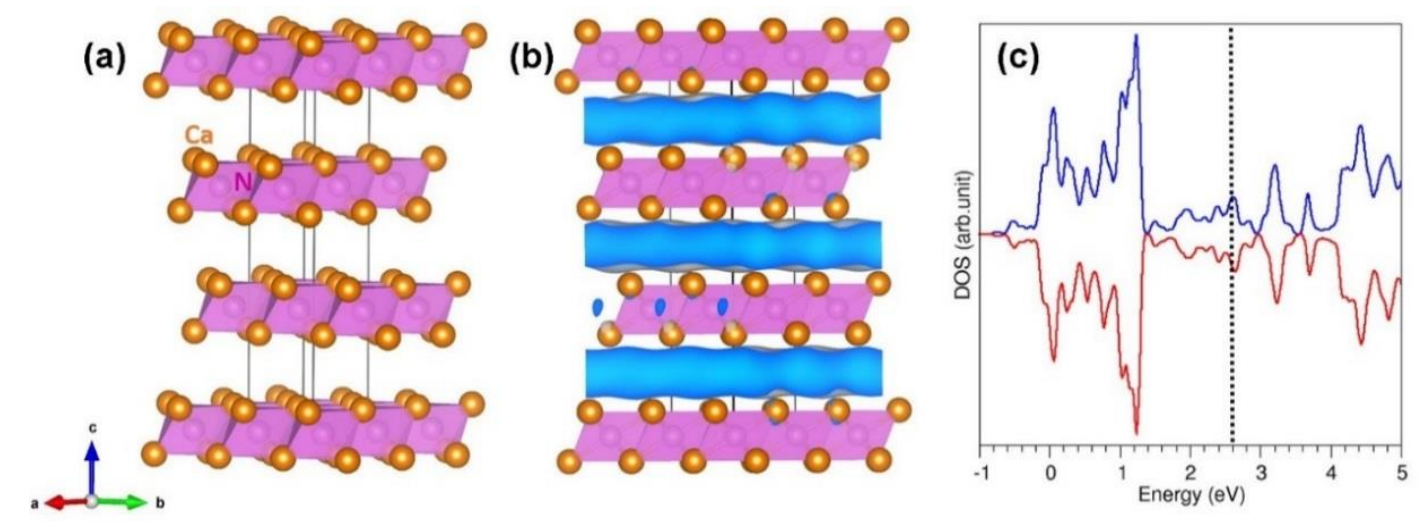

Figure 1. (a) The relaxed structure of bulk $\mathrm{Ca}_{2} \mathrm{~N}: \mathrm{e}^{-}$, (b) electrons confined two-dimensionally within layers and (c) DOS plot of bulk $\mathrm{Ca}_{2} \mathrm{~N}: \mathrm{e}^{-}$. Black dashed lines correspond to the Fermi energy level. 

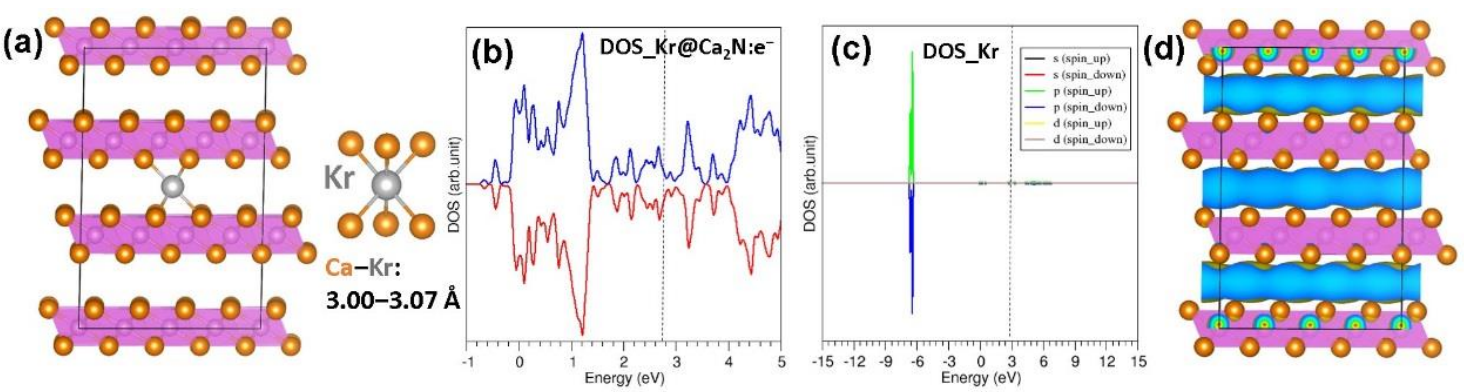

(e)
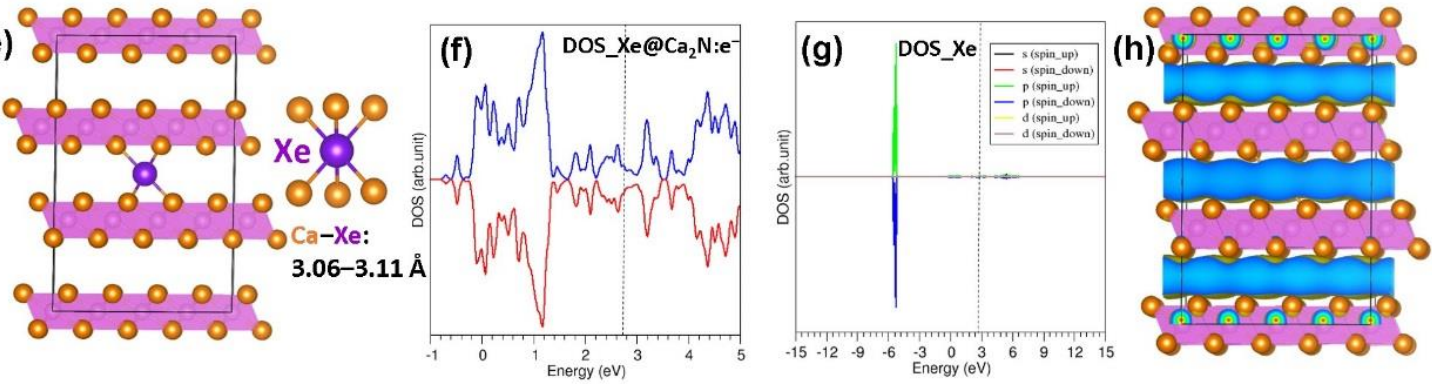

Figure 2. (a) Relaxed structure of $\mathrm{Kr}$ encapsulated within $\mathrm{Ca}_{2} \mathrm{~N}: \mathrm{e}^{-}$, (b) total DOS plot (c) atomic DOS plot of $\mathrm{Kr}(\mathrm{d})$ constant charge density plot showing electron distribution upon encapsulation and (eh) corresponding structures and plots calculated for Xe encapsulated within $\mathrm{Ca}_{2} \mathrm{~N}: \mathrm{e}^{-}$. 

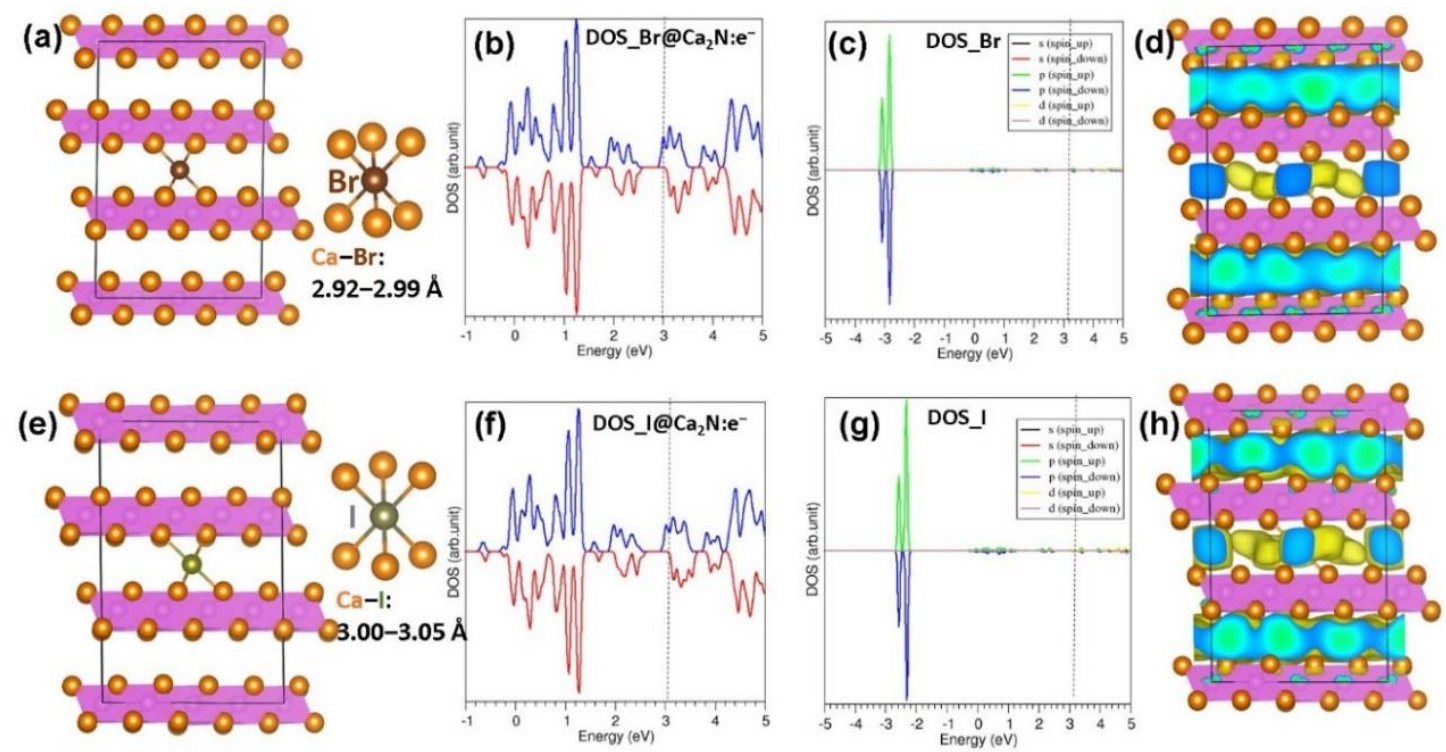

Figure 3. (a) Relaxed structure of Br encapsulated within $\mathrm{Ca}_{2} \mathrm{~N}: \mathrm{e}^{-}$, (b) total DOS plot (c) atomic DOS plot of $\mathrm{Br}(\mathrm{d})$ constant charge density plot showing electron distribution upon encapsulation and (eh) corresponding structures and plots calculated for the I encapsulated $\mathrm{Ca}_{2} \mathrm{~N}: \mathrm{e}^{-}$. 
(a)

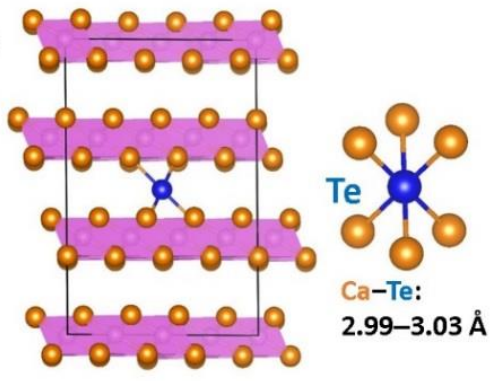

(c)

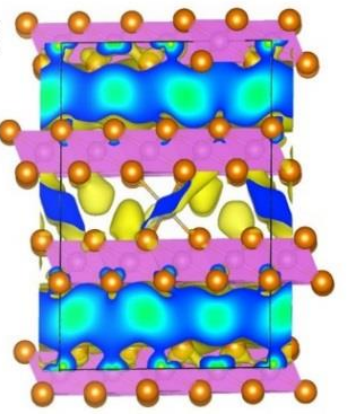

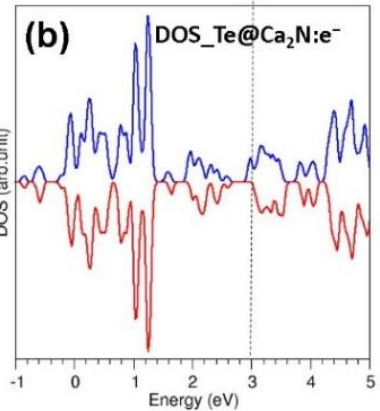

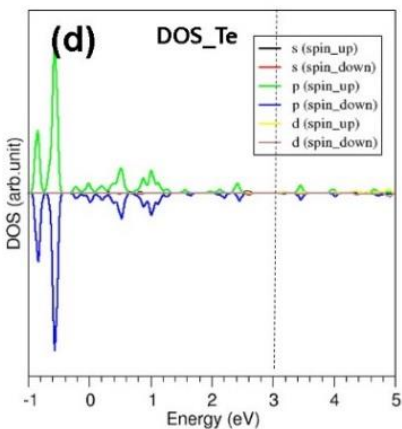

Figure 4. (a) Relaxed structure of Te encapsulated within $\mathrm{Ca}_{2} \mathrm{~N}: \mathrm{e}^{-}$, (b) total DOS plot (c) constant charge density plot showing electron distribution upon encapsulation and (d) atomic DOS plot of Te. 

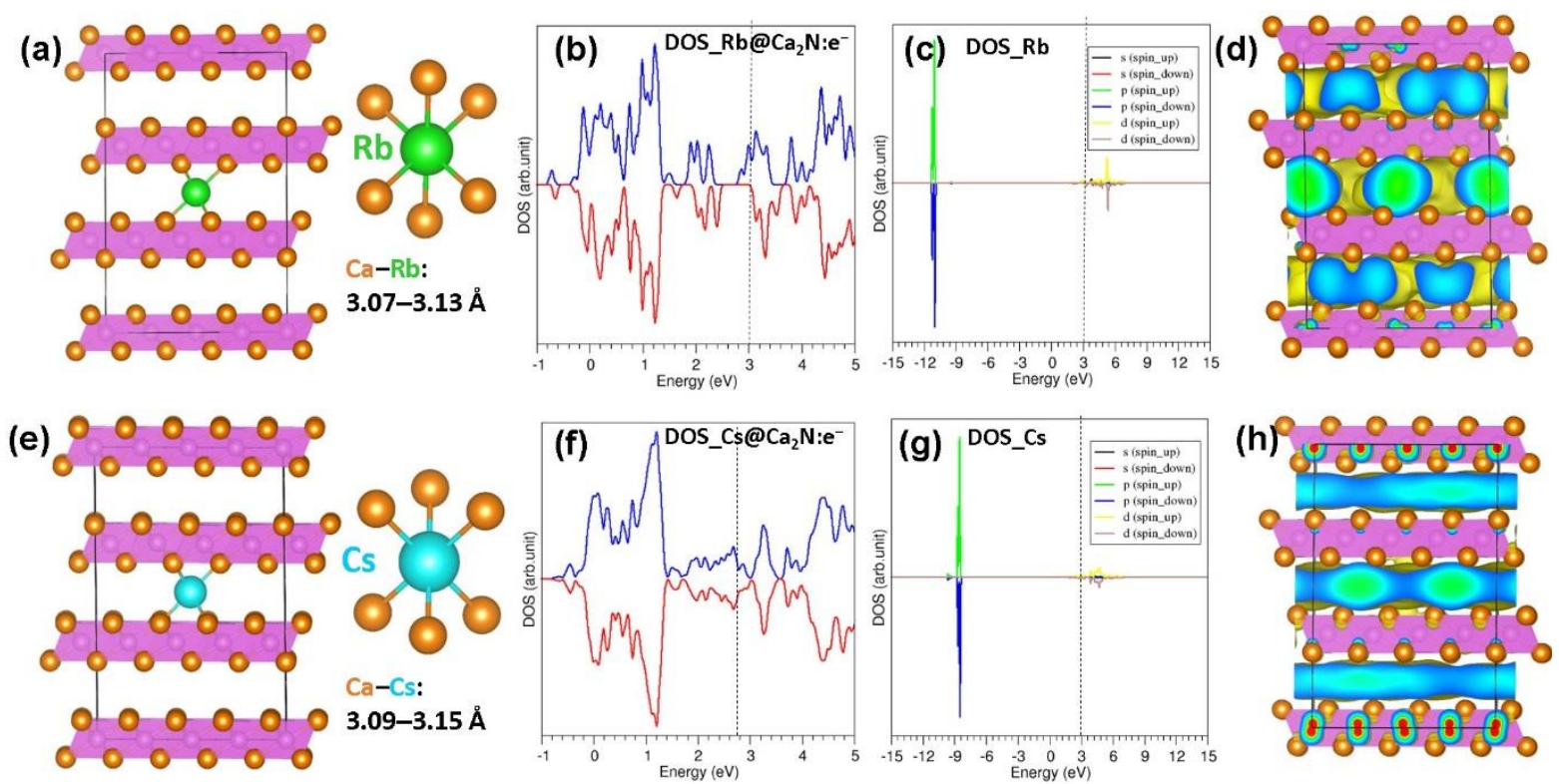

Figure 5. (a) Relaxed structure of Rb encapsulated within $\mathrm{Ca}_{2} \mathrm{~N}: \mathrm{e}^{-}$, (b) total DOS plot (c) atomic DOS plot of $\mathrm{Rb}(\mathrm{d})$ constant charge density plot showing electron distribution upon encapsulation and (eh) corresponding structures and plots calculated for the Cs encapsulated $\mathrm{Ca}_{2} \mathrm{~N}: \mathrm{e}^{-}$. 
(a)

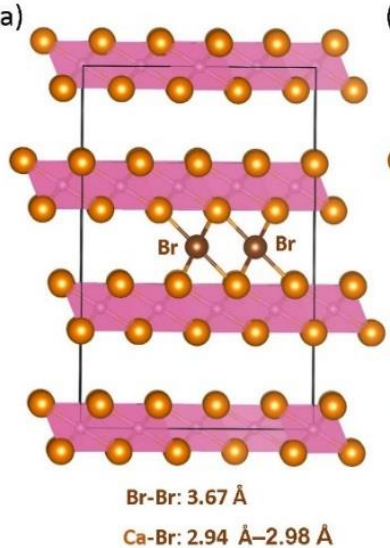

(b

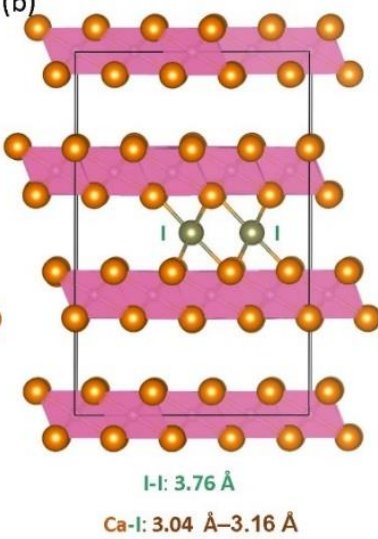

(c)
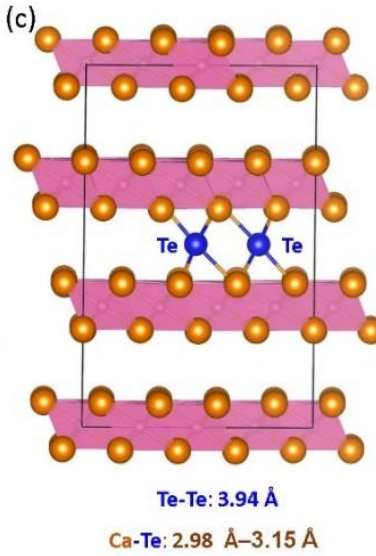

Figure 6. Relaxed structures of (a) $\mathrm{Br}_{2},(\mathrm{~b}) \mathrm{I}_{2}$ and (c) $\mathrm{Te}_{2}$ encapsulated in $\mathrm{Ca}_{2} \mathrm{~N}: \mathrm{e}^{-}$. 
(a) $\begin{array}{llllll}0 & 0 & 0 & 0 & 0 & 0 \\ 0 & 0 & 0 & 0 & 0 & 0 \\ 0 & 0 & 0 & 0\end{array}$

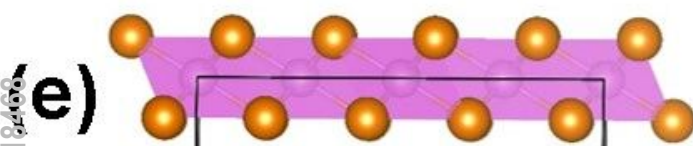

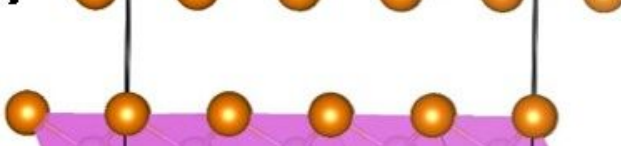

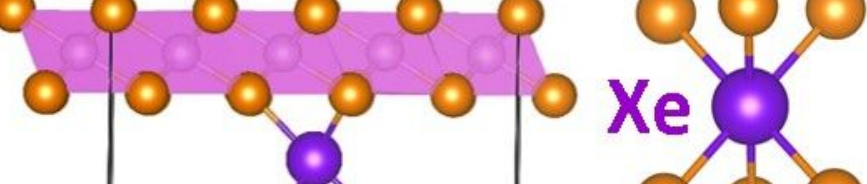
- o o o o 000

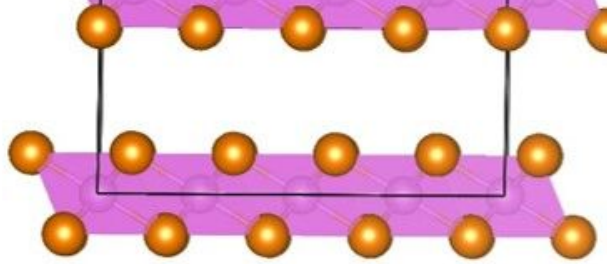
3.06-3.11 A

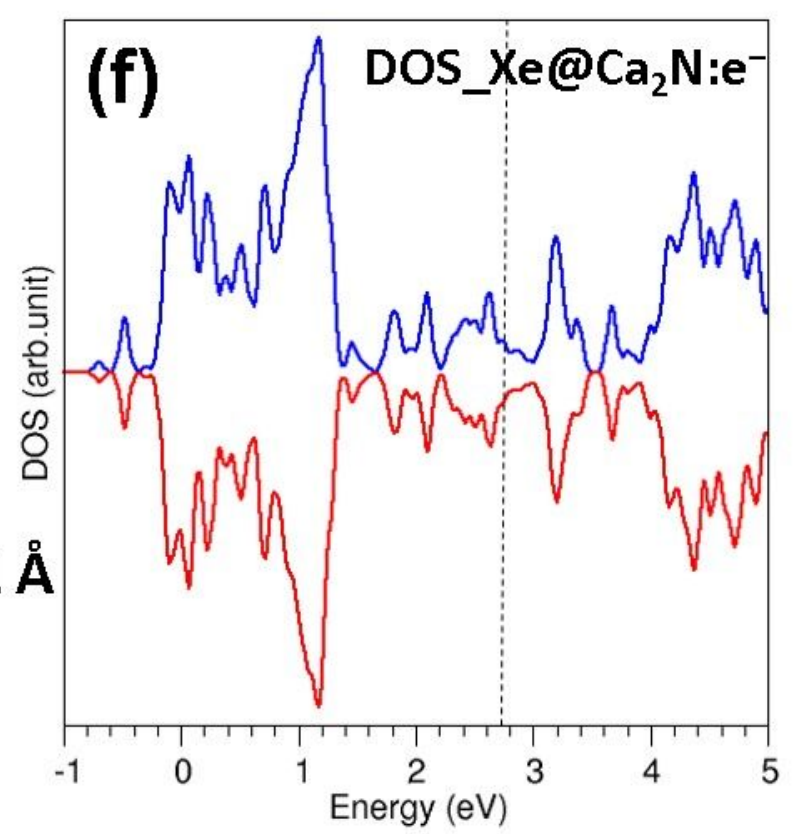

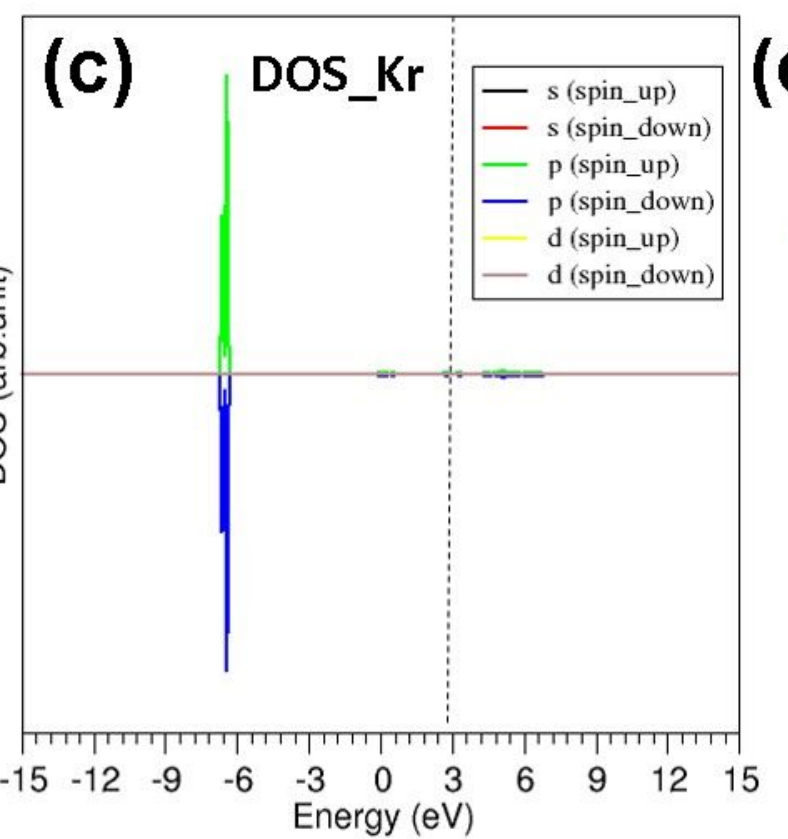

(d)
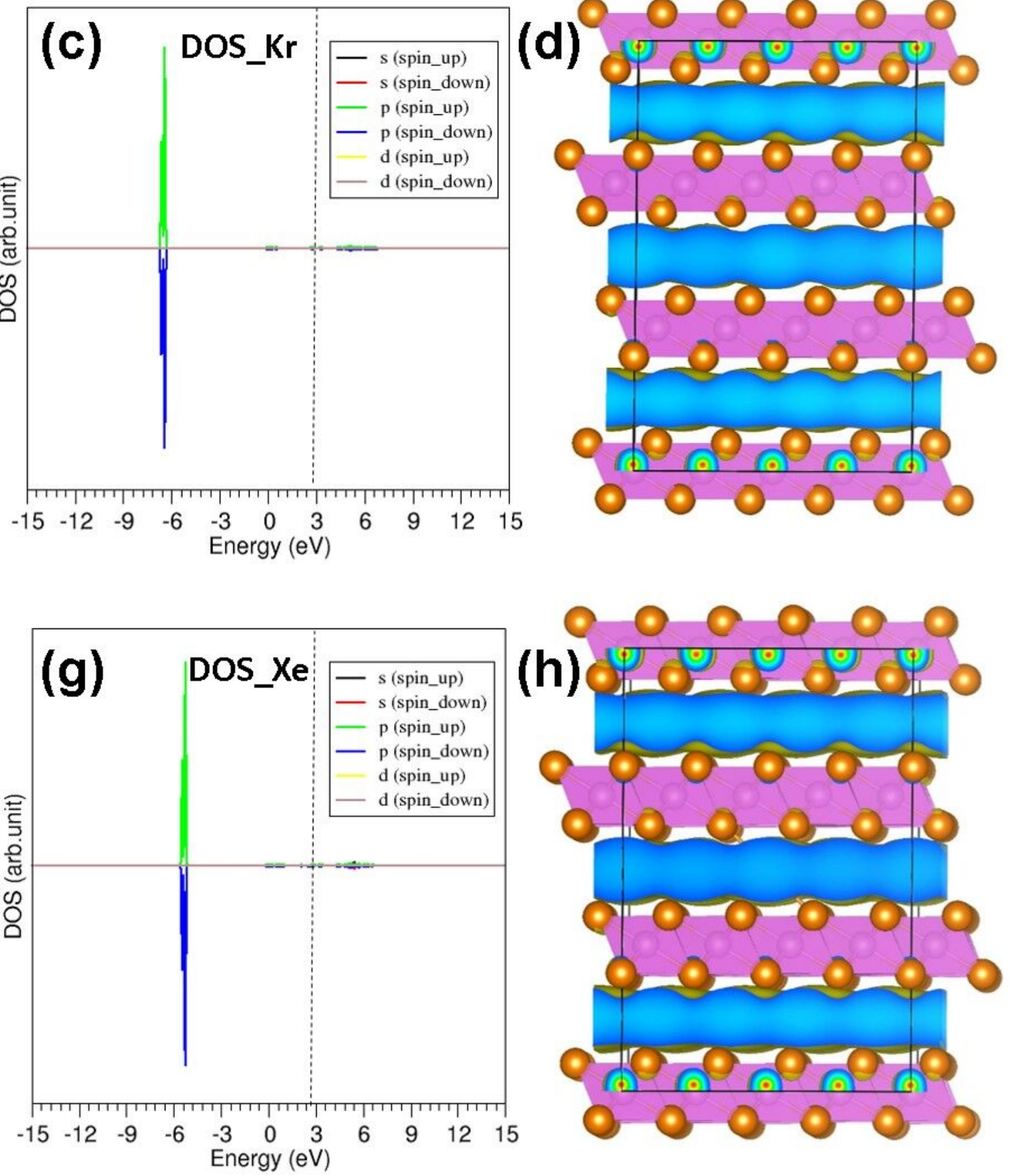

00000 (h) Q क- $-\mathrm{O}-\mathrm{O}$ $0.0-0,0=0$ ला० - $-0-0$ $0-0-0=0$

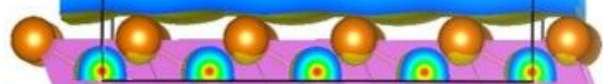




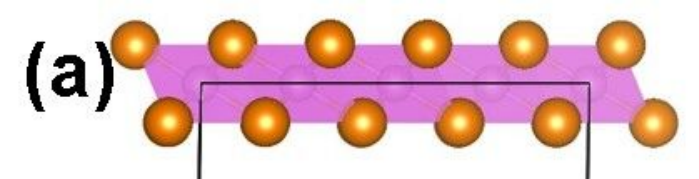

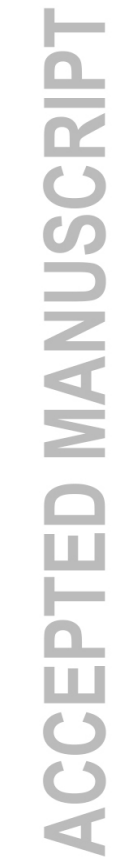

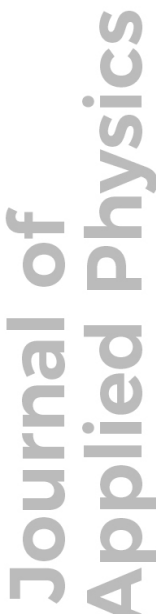

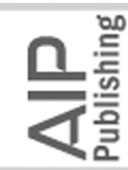

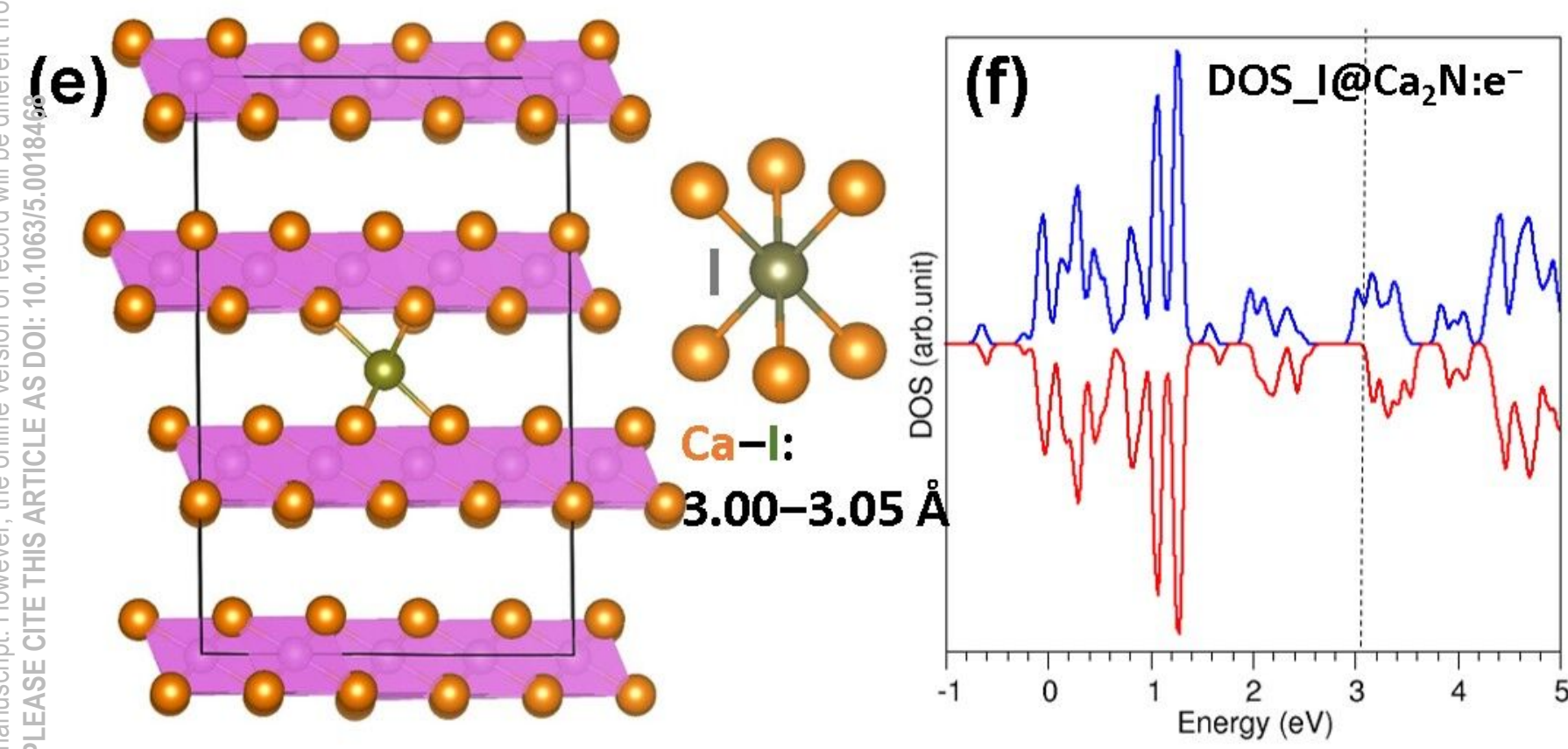

(d)
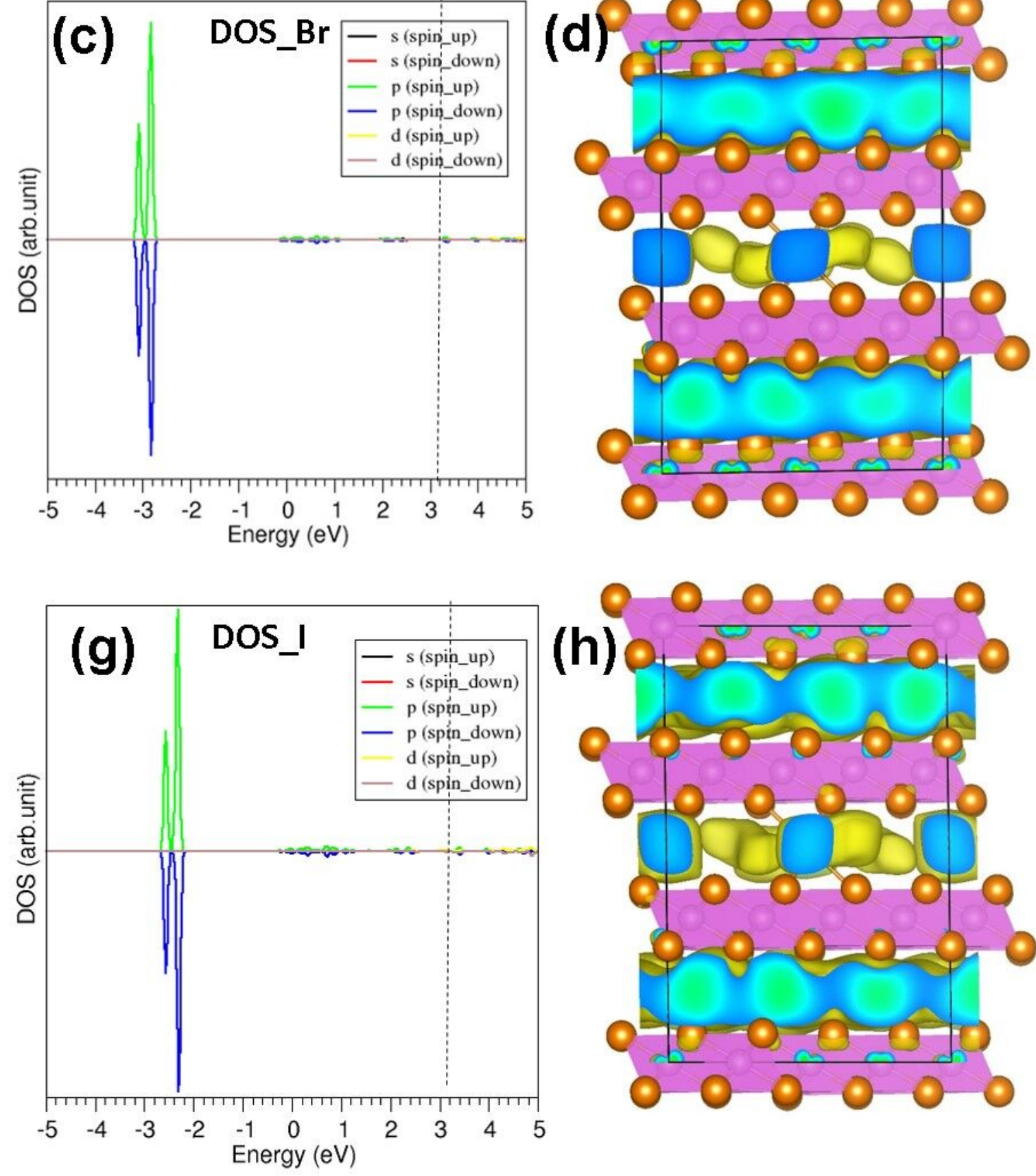

$\begin{array}{llllll}0 & 0 & 0 & 0 & 0 & 0\end{array}$ (h) $0.0-0-0.0$ $0.8-0.60$ $0-0-0-0 \%$ - 00 ofo

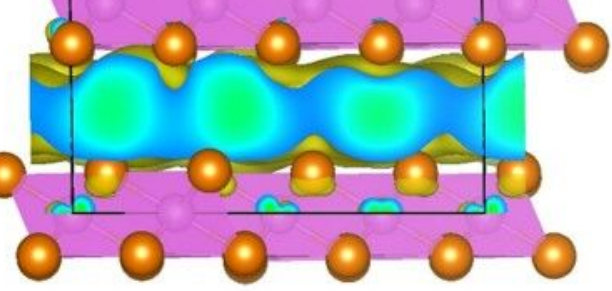


(a)

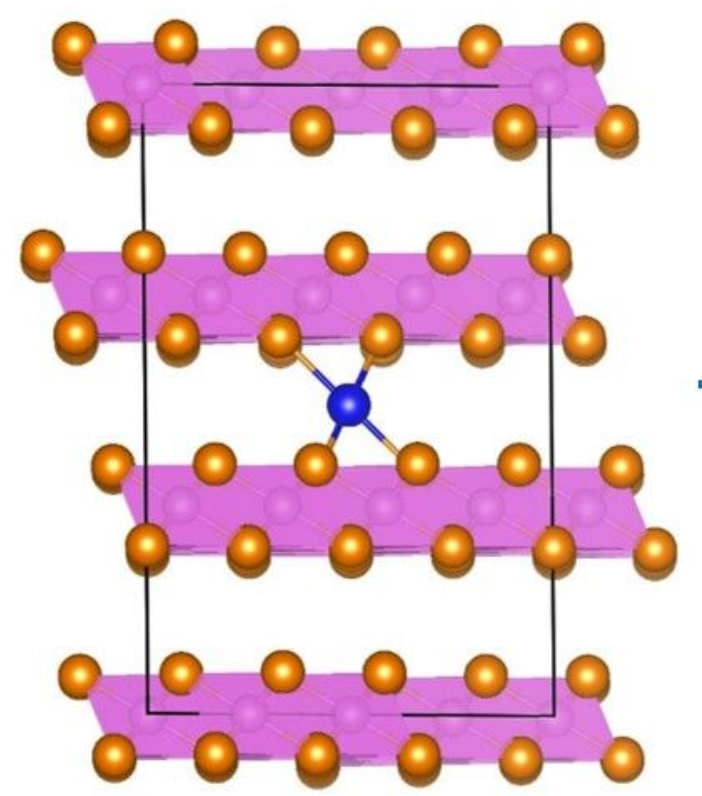

(c)

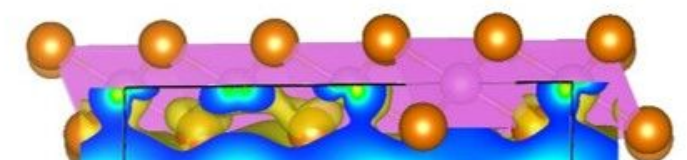

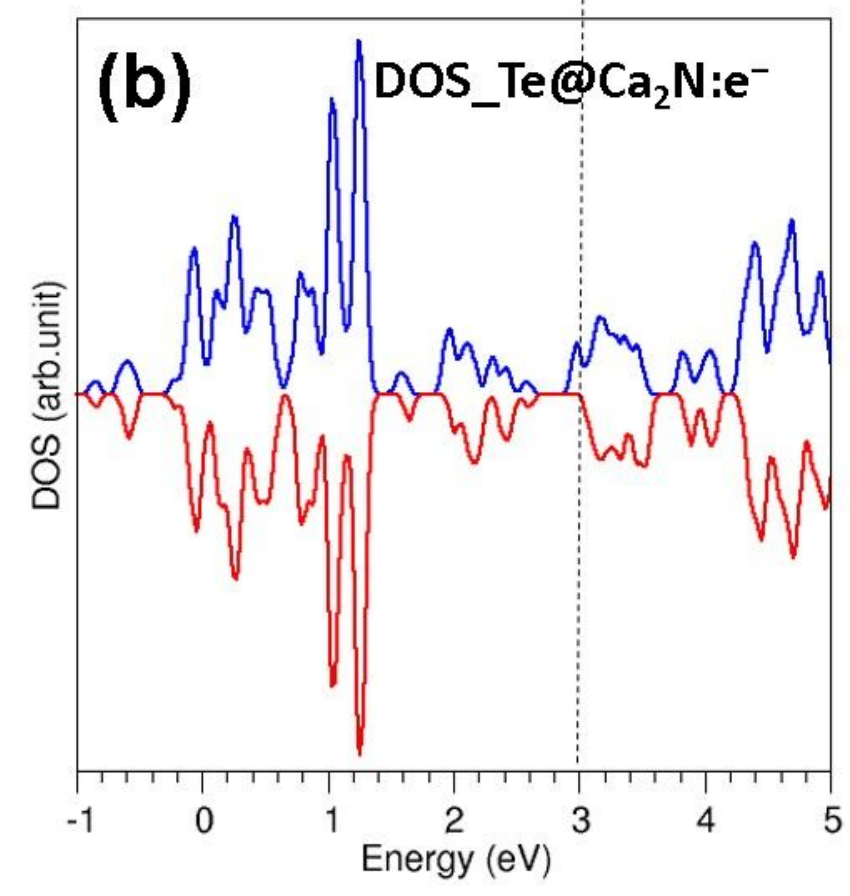

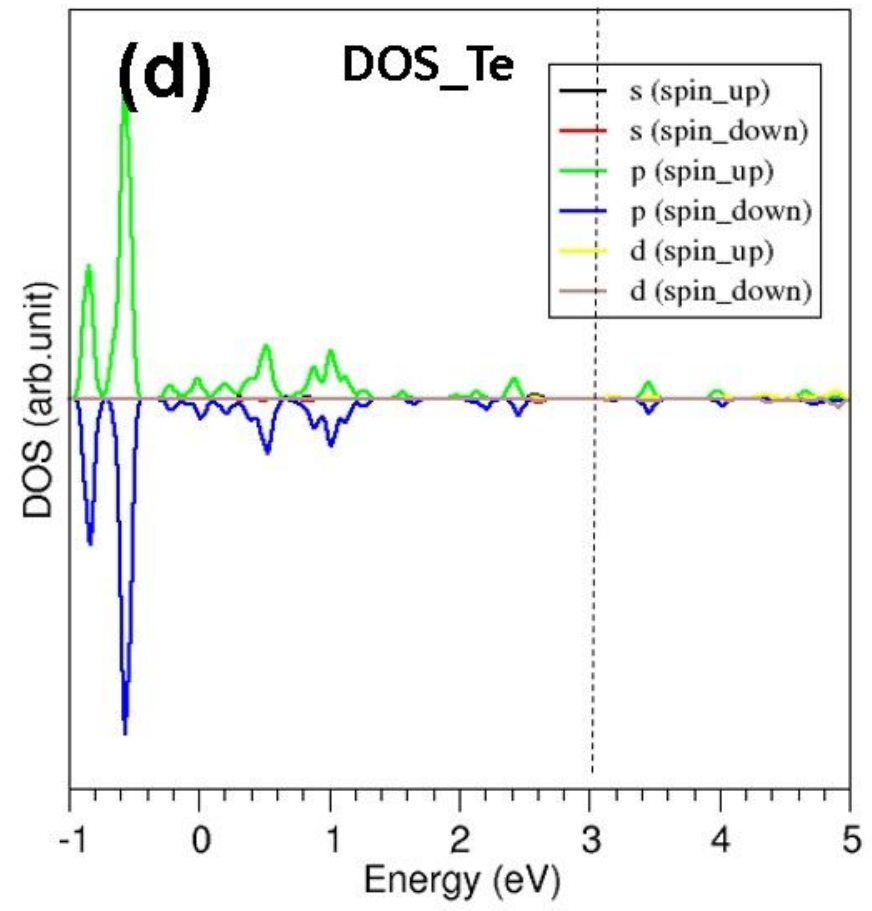


(a)

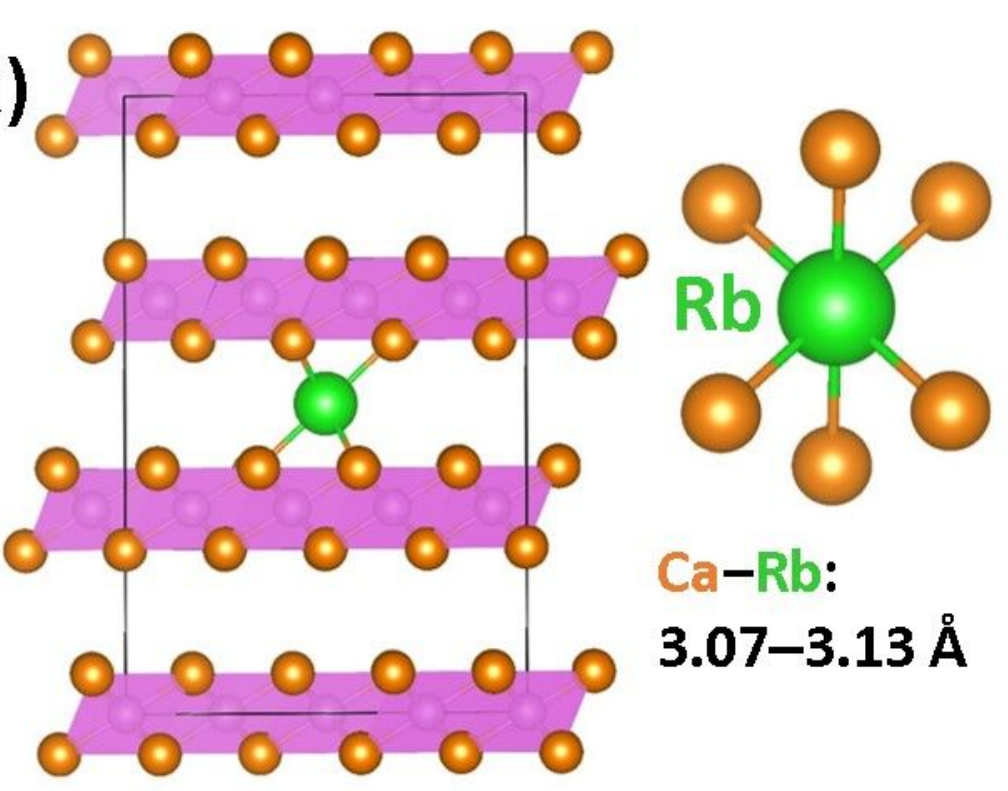

(e)
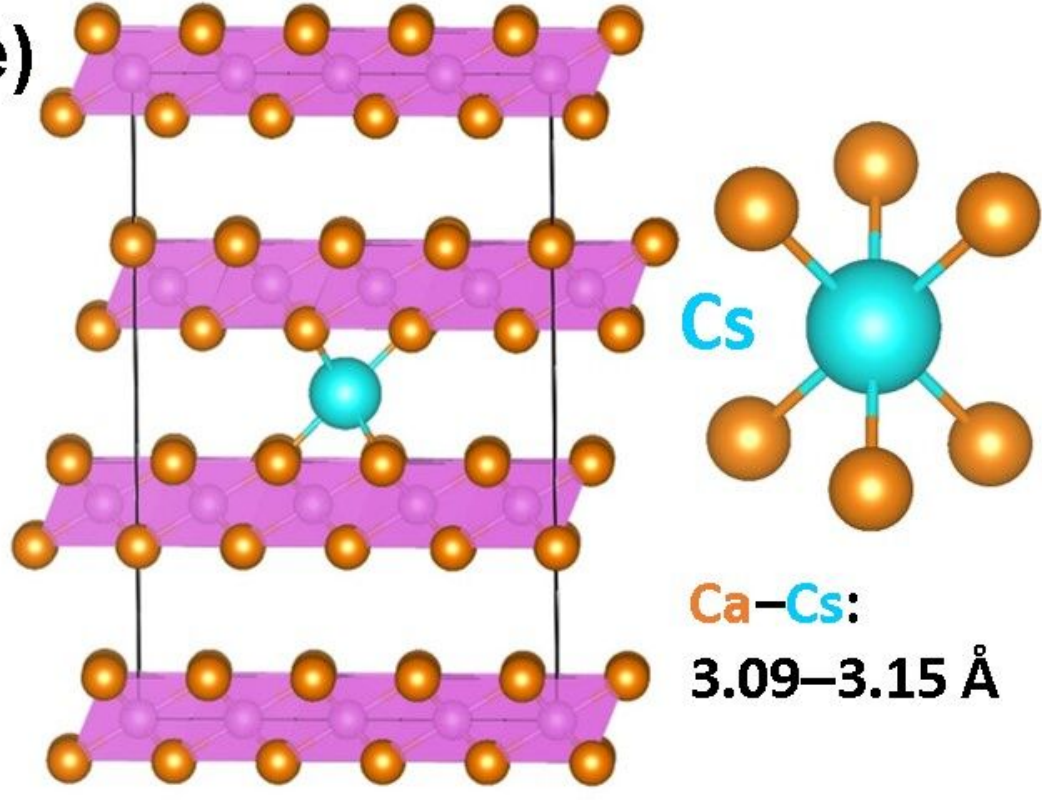

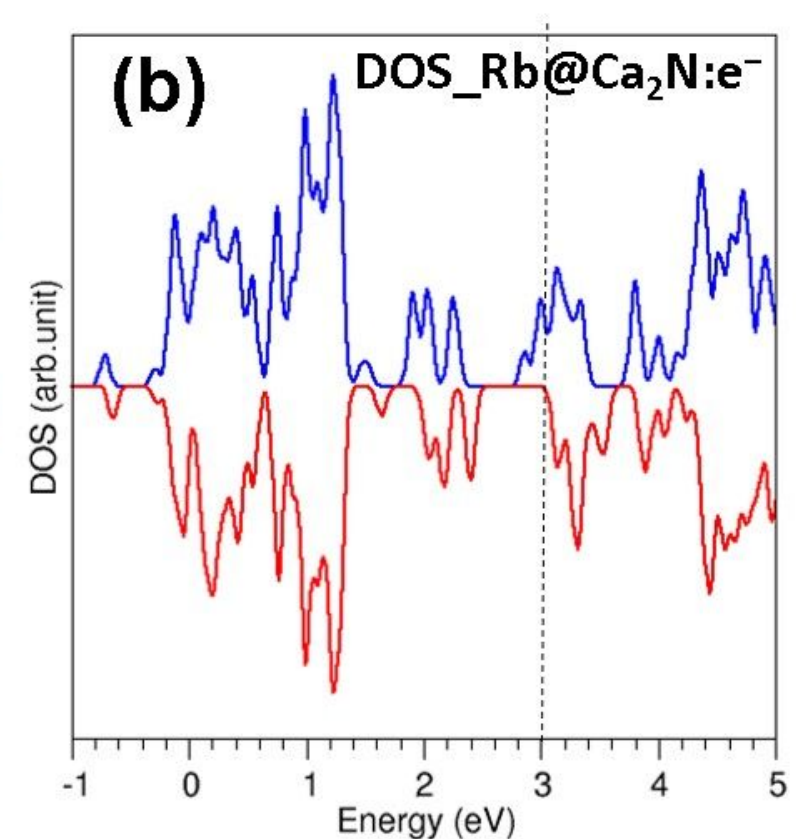

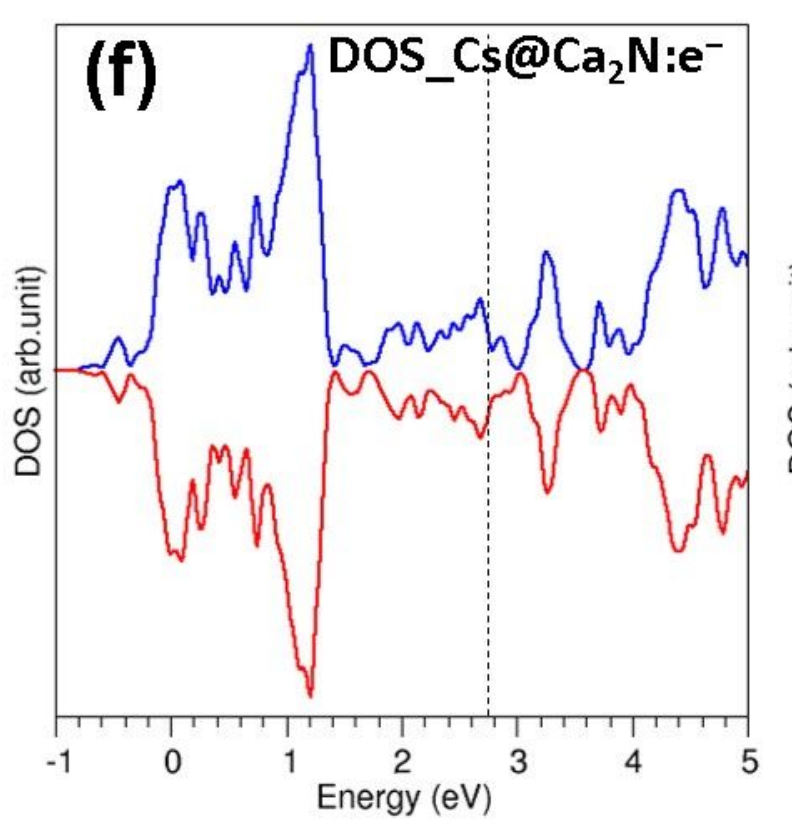

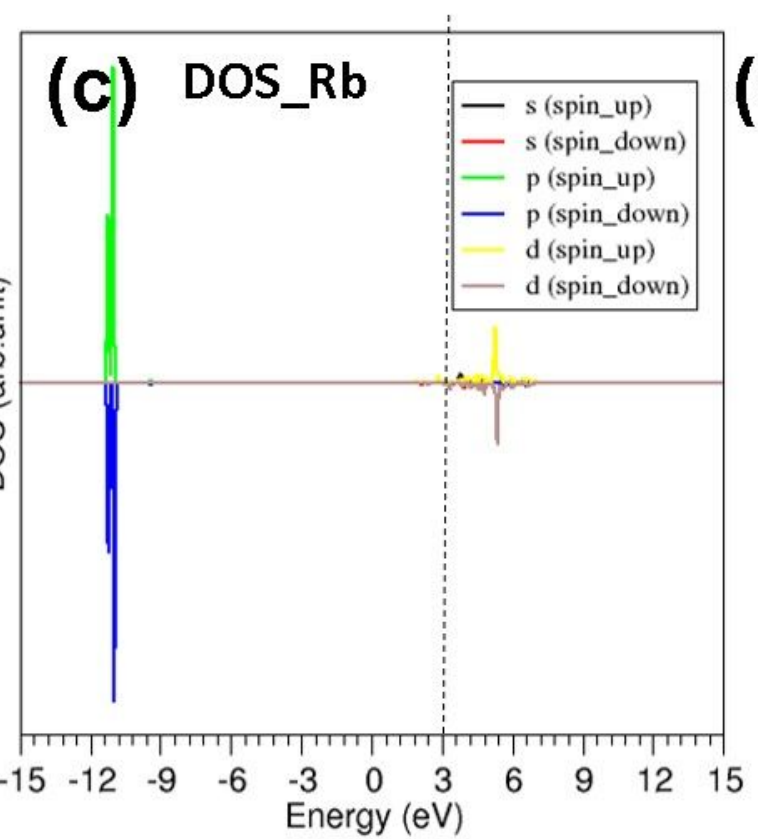

(d)

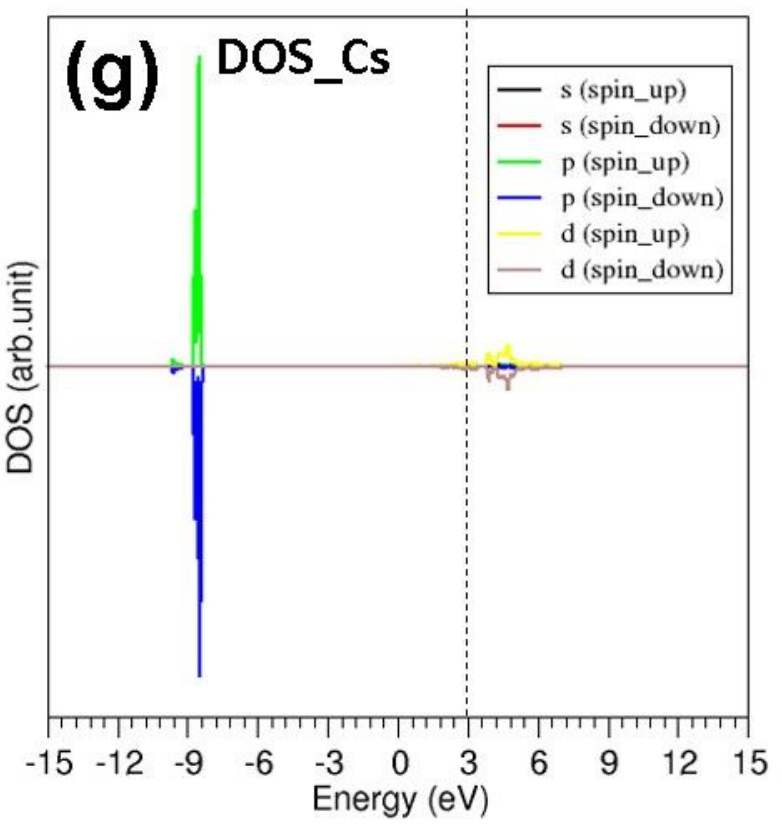

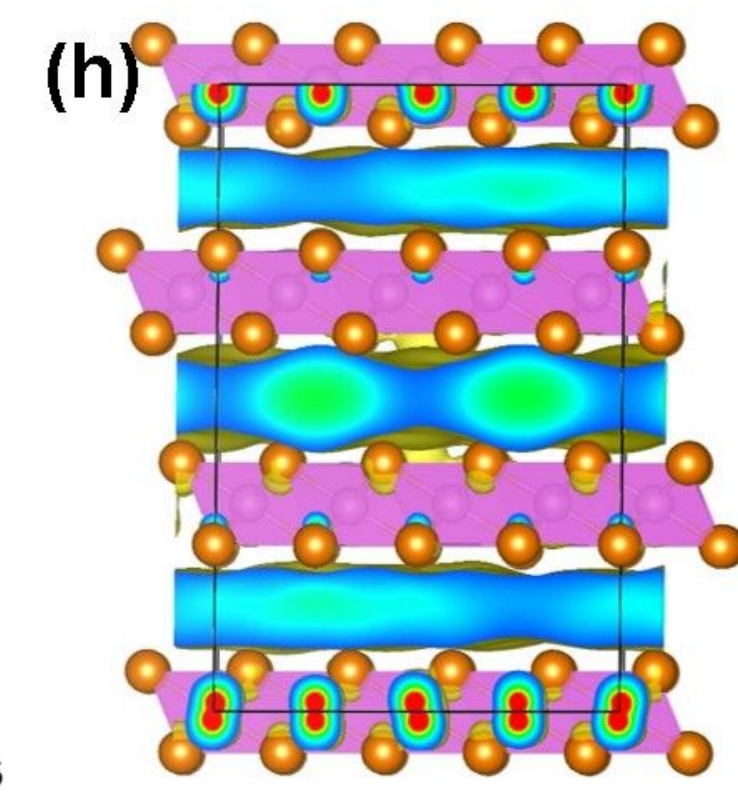

맺민 


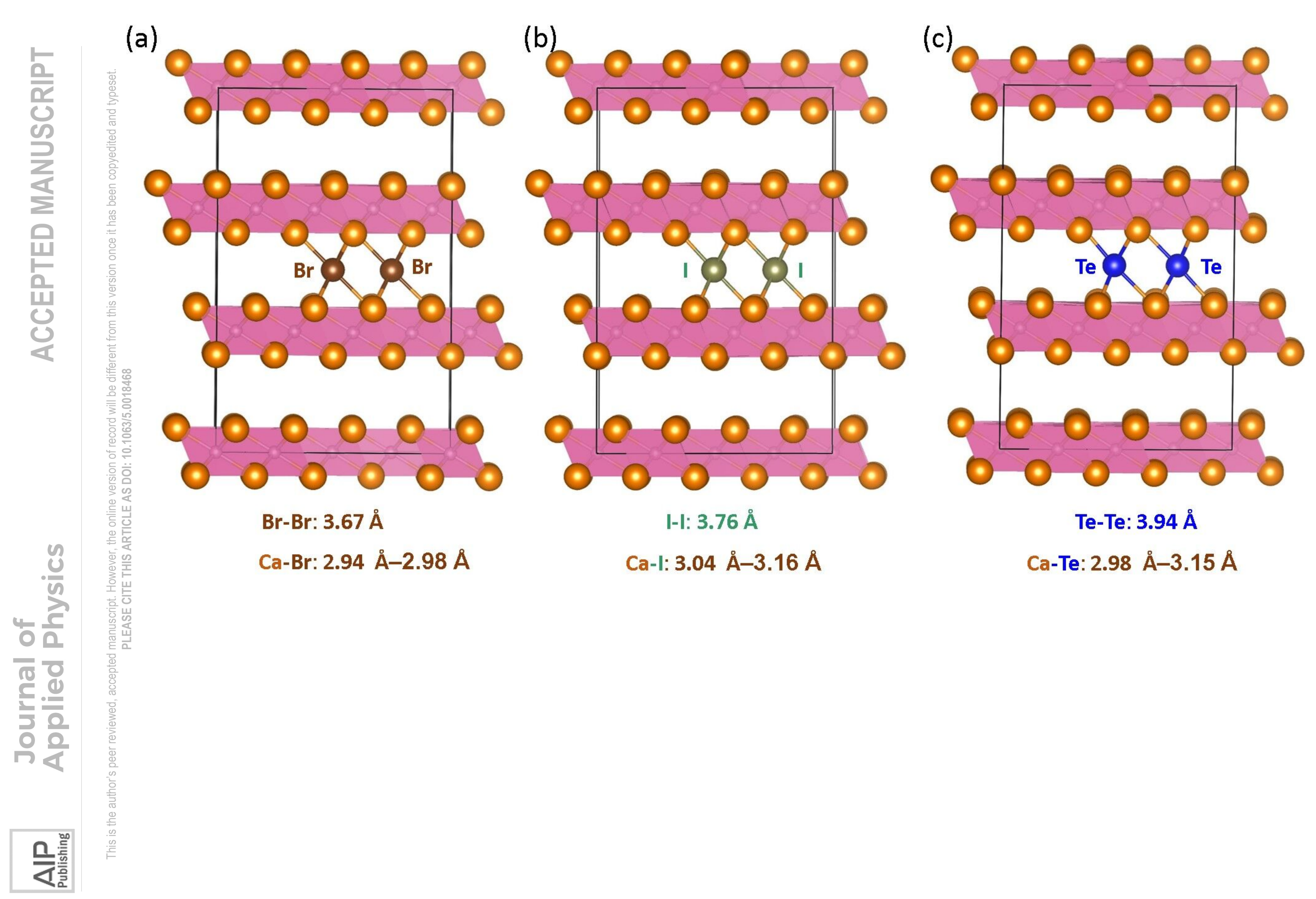

